\title{
A new technology for suspended sediment simulation in Lake Taihu, China: Combination of hydrodynamic modeling and remote sensing
}

\author{
Zhuo ZHANG, ${ }^{1,2}$ Changchun HUANG,,${ }^{1,2 *}$ Fei GUO, ${ }^{1,2}$ Zhiyao SONG,,${ }^{1,2}$ Di HU ${ }^{1,2}$ \\ ${ }^{1}$ Key Laboratory of Virtual Geographic Environment, Nanjing Normal University, Ministry of Education, Nanjing 210023; ${ }^{2}$ Jiangsu \\ Center for Collaborative Innovation in Geographical Information Resource Development and Application, Nanjing 210023, China
}

\begin{abstract}
Sediment resuspension is closely related to the endogenetic release of nutrients in Lake Taihu. Thus, understanding the factors associated with sediment resuspension is important. In this study, a new technology, which integrates a hydrodynamic model and remote sensing techniques, was applied to derive the distribution of the erosion flux and obtain the spatially variable critical shear stress. Then, the spatially variable critical shear stress was used in the sediment simulations at Lake Taihu. Compared to the traditional model, based on uniform values of critical shear stress, the new method, using variable values of critical shear stress calibrated from the Geostationary Ocean Color Imager (GOCI) data, significantly improved the sediment simulations at Lake Taihu. Based on the erosion flux from August 6-8, 2013, the correlations between erosion and wind speed, wind fetch, mud depth, and water depth were analyzed for different subsections and spots in Lake Taihu. The potential sources of error were also addressed. Further improvement of the model is necessary.
\end{abstract}

\section{INTRODUCTION}

The deterioration of freshwater in lakes and rivers has caused alarming increases of eutrophication levels, which in turn have led to frequent outbreaks of algal blooms in lakes, rivers and coastal areas that have affected the economic and social development in the surrounding regions. According to previous investigations, eutrophication is primarily caused by increasing amounts of industrial, agricultural and anthropogenic waste discharged into water (Schladow and Hamilton, 1997). Nevertheless, in some shallow lakes, controlling nutrient inputs still does not prevent algal blooms because large amounts of nutrients such as phosphorus and nitrogen are released from suspended sediment on windy days (Qin et al., 2007; Qin, 2009; Kaitaranta et al., 2013). Recent remote sensing studies (Fan et al., 2004; Li et al., 2004; Zhu et al., 2005; Huang et al., 2015) have indicated that

Corresponding author: huangchangchun_aaa@163.com

Edited by: Marco Toffolon, University of Trento, Italy

Key words: Sediment resuspension; erosion; numerical simulation; GOCI.

Received: 29 March 2018.

Accepted: 15 January 2019.

This work is licensed under a Creative Commons Attribution NonCommercial 4.0 License (CC BY-NC 4.0).

(C) Copyright Z. Zhang et al., 2019

Licensee PAGEPress, Italy

J. Limnol., 2019; 78(1): 121-134

DOI: 10.4081/jlimnol.2019.1813 a significant amount of phosphorus has been released from sediment resuspension in Lake Taihu.

Many scholars have investigated the process of sediment resuspension to better understand the cause of eutrophication and to control endogenetic pollution ( $\mathrm{Li}$ et al., 2007, 2009). Resuspension depends on the combined actions of many factors, such as waves, currents, the bed grain size, the bulk characteristics of the bed material, and biogenic influences. In shallow lakes, wind-driven waves are considered the dominant force of sediment erosion and transportation (Douglas and Rippey, 2000; Chung et al., 2009). Therefore, wave characteristics in shallow lakes have led to increased interest in improving estimates of sediment resuspension (Luo et al., 2004). Apart from external dynamics like waves, current, and wind, the properties of the bed load determine the critical shear stress (Maa et al., 2008). When the bottom stress, under the interaction of waves and current, exceeds the critical shear stress, the bottom shear stress can entrain the sediment and cause sediment resuspension (Thompson et al., 2011). Hence, correctly estimating the critical shear stress is crucial for studying sediment resuspension.

Due to the limitations of high-resolution and synchronous spatial-temporal observations of spot sampling methods, numerical simulation has become a feasible approach to obtain and predict the spatial distribution of suspended sediments in rivers, lakes and offshore (Hu et al., 2006; Elliott et al., 2007; Zhang et al., 2008). Some famous models include ECOMSED (Zheng et al., 2003), EFDC (Hamrick, 1992a, 1992b), FVCOM (Chen et al., 2003) and others. All the applications of the above models demonstrate that a correct simulation result depends on a series of elaborate parameter calibrations (Mao et al., 2007; Hu et al., 2011). Consequently, the uncertainty in the parameter calibration limits the accuracy of the simulation results (Huang et al., 2012). 
With advances in remote sensing technology, synchronous and timely images recording the near-surface optic characteristics of waters are now available over large areas. After geometric and atmospheric corrections, the sediment concentration near the surface can be derived using a retrieval model, based on the reflectance. Geostationary Ocean Color Image (GOCI) sensing, covering the northeast Asian seas, provides high spatiotemporally variable sediment concentrations with a horizontal resolution of $500 \mathrm{~m}$ at hourly intervals for 8 hours each day (Cho et al., 2010). Thus, the GOCI data can be applied to calibrate the parameters of sediment resuspension models. Ge et al. (2015) developed a new methodology that integrated GOCI data and numerical modeling and used it to estimate the critical bottom shear stress of erosion in the Changjiang Estuary. However, in shallow lakes such as Lake Taihu, the spatial distribution of resuspension, represented by the erosion flux in this study, has never been analyzed due to the shortage of high-resolution data, as the lack of data prevented sediment models from being accurately calibrated. Therefore, the major focus of this study was to analyze the factors that affect sediment resuspension and to demonstrate the utility of using remote sensing to calibrate a sophisticated sediment model.

In this study, we first derived the distribution of the erosion flux in Lake Taihu through a combination of modeling and GOCI sensing. Then, the critical shear stress of erosion was obtained from the erosion flux. Next, the simulation results produced using the GOCI derived critical shear stress and the spatially uniform critical shear stress were compared to each other and to buoy data. Finally, we discussed the factors affecting the erosion flux in different areas, as well as the shortcomings of the sediment model. The structure of the paper is as follows: In the "Methods" section, the study areas and the investigation methods are described; in the following headings, the methodology of combining hydrodynamic modeling and GOCI sensing is introduced; in the "Results" section, the simulation results are shown and compared; in the "Discussion" section, the factors that influence the distribution of the erosion flux and the sediment simulation are discussed.

\section{METHODS}

\section{Description of Lake Taihu}

Lake Taihu is a eutrophic and shallow lake situated in Southeast China, with a water surface area of approximately $2338 \mathrm{~km}^{2}$ and a mean depth of $1.9 \mathrm{~m}$. The average length of the lake is $68.5 \mathrm{~km}$, and the average width is $34 \mathrm{~km}$. It contains a high-density river network with approximately 219 rivers and tributaries that inflows to, and outflows from, the lake. The annual average temperature of the lake is $17.1^{\circ} \mathrm{C}$. The retention time of water in the lake is approximately 284 days. Generally, water enters the lake from the west and flows out to the east. According to the runoff pattern, nine rivers are connected to Lake Taihu, including five inflow rivers and four outflow rivers. The lake basin has a lower elevation at the western part than the east part, with the deep region deviating from the lake center to the west. Compared to the complex bank in the east, the western bank line is smooth and straight. The lake bed is covered by the mud composed of silt and clay with grain sizes ranging between 2 and 20 micrometers. Most of the mud is distributed in the western and northern parts of the lake.

The plain area surrounding Lake Taihu is dominated by a monsoon climate, with an annual average air temperature of $14.6-16.2^{\circ} \mathrm{C}$. The wind direction frequency data suggest that the direction of the prevailing wind at Lake Taihu is southeast in the summer, and the dominant wind speed ranges from $1.7-6.0 \mathrm{~m} / \mathrm{s}$, accounting for $70 \%$ of the wind events. The southeastern wind (SE) has often been considered a predominant driving force that affects the overall current circulation in Lake Taihu (Pang et al., 2006).

Fig. 1 shows the geometry of Lake Taihu. The lake can be separated into seven major subsections according to hydrodynamic conditions and ecological functions: Meiliang Bay (MB), Central Lake (CL), Northwestern Lake (NWL), Southwestern Lake (SWL), Gonghu Lake (GL), Eastern Lake (EL) and Eastern Bay (EB). Lake Taihu is characterized by hyper-eutrophication and algal blooms. Long-term accumulation of high nutrient inflows has caused the lakebed mud to become full of pollutants, which are often released due to sediment resuspension on windy days, causing endogenous pollution. Consequently, harmful algal blooms in Lake Taihu are worsening each year, especially in the MB and the Zhushan Bay in the NWL.

\section{Description of the models}

\section{Hydrodynamic model}

Three-dimensional shallow water equations are composed of the continuity equation, the momentum equation, and the free surface equation.

$$
\begin{aligned}
& \frac{\partial u}{\partial t}+u \frac{\partial u}{\partial x}+v \frac{\partial u}{\partial y}+w \frac{\partial w}{\partial z}-f v=-g \frac{\partial \eta}{\partial x}-g \frac{\partial}{\partial x} \int_{z}^{\rho} \frac{\rho-\rho_{0}}{\rho_{0}} d z+\frac{\partial}{\partial z}\left(v_{T} \frac{\partial u}{\partial z}\right)+F_{x} \text { (eq. 1) } \\
& \frac{\partial v}{\partial t}+u \frac{\partial v}{\partial x}+v \frac{\partial v}{\partial y}+w \frac{\partial v}{\partial z}+f u=-g \frac{\partial \eta}{\partial y}-g \frac{\partial}{\partial x} \int_{z} \frac{\rho-\rho_{0}}{\rho_{0}} d z+\frac{\partial}{\partial z}\left(v_{T} \frac{\partial v}{\partial z}\right)+F_{y} \quad \text { (eq. 2) } \\
& \frac{\partial u}{\partial x}+\frac{\partial v}{\partial y}+\frac{\partial w}{\partial z}=0 \\
& \frac{\partial \eta}{\partial t}+\frac{\partial}{\partial x} \int_{-h}^{n} u d z+\frac{\partial}{\partial y} \int_{-h}^{\prime \prime} v d z=0
\end{aligned}
$$


where $u, v$, and $w$ are the velocity components of flow in the $x, y$ and $z$ directions, respectively, $\mathrm{t}$ is the time, $\eta$ is water level, $f$ is the Coriolis parameter, $g$ is the gravitational acceleration, $r$ is the density of water, $r_{0}$ is the reference density of water, $u_{T}$ is the vertical turbulent viscosity coefficient, $F_{x}$ and $F_{y}$ are diffusion of two horizontal directions (see Appendix A), and $h$ is the static water depth denoting the vertical length between the static water level and bottom of the lake with the positive direction downwards.

\section{Suspended sediment model}

$\frac{\partial S}{\partial t}+\frac{\partial u S}{\partial x}+\frac{\partial v S}{\partial y}+\frac{\partial\left(w-\omega_{s}\right) S}{\partial z}=\frac{\partial}{\partial z}\left(v_{s} \frac{\partial S}{\partial z}\right)+F_{s}$

where $S$ is the suspended sediment concentration, $w_{s}$ is the settling velocity of the sediment, $F_{s}$ is horizontal diffusion (see Appendix A), and $u_{s}$ is the vertical diffusion coefficient.

The bottom boundary condition for sediment are:

$-\left.v_{s} \frac{\partial S}{\partial z}\right|_{-h}=E \quad$ and $\quad \omega_{s} S(-h)=D$

where $E\left(\mathrm{~kg} \mathrm{~m}^{-2} \mathrm{~h}^{-1}\right)$ denotes the erosion flux, also called resuspension and $D\left(\mathrm{~kg} \mathrm{~m}^{-2} \mathrm{~h}^{-1}\right)$ denotes the deposition flux.

The criterion for judging erosion and deposition of the near-bed suspended sediment is crucial for the sediment simulation. There are mainly two types of criterions for calculating the sediment erosion flux at the bed: critical shear stress and sediment carrying capacity. Although they have different forms, their essence is identical (Li et al., 2008). Here we chose the critical stress method (Gailani et al., 1991, Warner et al., 2008) to judge erosion flux:

$E=\left\{\begin{array}{cc}(1-\delta) M\left(\tau_{b} / \tau_{c e}-1\right) & \left(\tau_{b}>\tau_{c e}\right) \\ 0 & \left(\tau_{b} \leq \tau_{c e}\right)\end{array}\right.$

where $M$ is the erosion rate with the same unit as $E, t_{c e}(\mathrm{~N}$ $\left.\mathrm{m}^{-2}\right)$ is the critical shear stress for erosion, $t_{b}\left(\mathrm{~N} \mathrm{~m}^{-2}\right)$ is bottom shear stress, and $d$ is the sediment porosity.

The waves play a crucial role in disturbing the bottom sediments as well as the currents. The bottom shear stress under the combined effect of the waves and currents can be estimated by (Xin, 1997):

$\tau_{b}=\rho\left[C_{d} U^{2}+\frac{1}{8} f_{w} u_{w}^{2}+\frac{B}{\pi}\left(2 C_{d} f_{w}\right)^{0.5} U u_{w}\right]$

where $r$ is the water density, $U$ is the current velocity, $u_{w}$ is the wave orbital velocity at bed, $C_{d}$ is the drag coefficient, $f_{w}$ is the wave friction coefficient and $B$ is a parameter reflecting the interaction between current and wave: if the wave propagates along the current $B=0.917$; against the current, $B=-0.1983$; in any other case $B=0.359$.

The mass flux by erosion and deposition follows the natural sediment movement. When resuspension and settlement reach a balance in uniform flow, the sediment concentration distribution should be consistent with
Rouse (1938) formula, which was verified in the supplementary section (Appendix B).

\section{Wind wave model}

According to previous investigations (Luo et al., 2004), SMB model is suggested to compute the wind wave in Lake Taihu. The expressions of SMB model are as follows:

$\frac{g H_{s}}{W^{2}}=0.283 \tanh \left[0.530\left(\frac{g H}{W^{2}}\right)^{0.75}\right] \cdot \tanh \left[\frac{0.0125\left(\frac{g F}{W^{2}}\right)^{0.42}}{\tanh \left(0.530\left(\frac{g H}{W^{2}}\right)^{0.75}\right)}\right]$

$$
\frac{g T_{s}}{2 \pi W}=1.20 \tanh \left[0.833\left(\frac{g H}{W^{2}}\right)\right] \cdot \tanh \left[\frac{0.077\left(\frac{g F}{W^{2}}\right)^{0.25}}{\tanh \left(0.833\left(\frac{g H}{W^{2}}\right)^{0.375}\right.}\right]
$$

Where $H_{s}$ is the significant wave height, $T_{s}$ is the significant wave period, $H$ is the total water depth, $F$ is the fetch length, and $W$ is the wind speed.

\section{Numeral solution}

In addition to the above equations, the surface, bottom, and lateral boundary conditions should be included to obtain a numerical solution. The wind-induced shear stress was set as the surface boundary condition through the empirical wind drag formula (Large and Pond, 1981). The bottom stress was set as the bottom boundary condition according to the log profile near the bed. The time-dependent flux of inflows and outflows around Taihu Lake was given as the lateral boundary condition.

We used the Untrim (Unstructured grid TRIM) model as the hydrodynamic model and applied the finite volume method to discretize the equations (Casulli and Walters, 2000; Casulli and Zanolli, 2005). The Mellor-Yamada model (Mellor and Yamada, 1982) was applied to capture the sub-mesh eddy viscosity. The numerical discretization of the above models goes beyond the aim of this study, and therefore, it will not be discussed. The interested reader is referred to Casulli and Cattani (1993), Casulli and Walters, (2000), Casulli and Zanolli (2005) for additional information on the numerical scheme and Zhang et al. (2016) and Kong et al. (2013) for advection and diffusion transport.

\section{The GOCI sensing}

GOCI level-1b satellite image data from August 6, 2013 were downloaded from the Korea Ocean Satellite Center. A geometric correction was conducted using an ENVI (Environment for Visualizing Images) software package, and the atmospheric correction was completed based on the radiative transfer calculations from the second simulation of the satellite signal in the solar 
spectrum (6S model). This process was validated for the full clear-sky scenes. Here a three-band retrieval model was developed, in which the iterative optimization algorithm (Gitelson et al., 2007) was used to determine the optimal spectral bands for estimating the concentration of the average suspended sediment in optical depth. The model can be expressed by:

$$
\begin{gathered}
S_{r}=10^{f} \\
f=2.314 /\left\{1+\exp \left[-\left(\frac{R(745)+R(680)}{R(555)}-0.6263\right) / 0.431\right]\right\}
\end{gathered}
$$

where $S_{r}$ is the retrieval concentration, $R$ denotes the reflectance and 745, 680 and 555 are the wavelengths of the three bands. The detail and validation of this retrieval model are provided in the work by Huang et al. (2015).

\section{Combination of the model and GOCI sensing}

\section{Derivation of erosion flux}

Through the integration in the vertical direction and the application of boundary conditions on the surface and bottom, eq. (5) can be transferred into the following equation (see Appendix C)

$$
\int_{t l}^{2} E d t=\int_{-h}^{v^{2}} S\left(t_{2}\right) d z-\int_{-h}^{v t} S\left(t_{t}\right) d z+\int_{l l}^{t^{2}} F_{d d t^{2}} d t+\int_{t l}^{2} D d t
$$

Where the left term denotes the erosion flux during the interval from $t_{1}$ to $t_{2}$, the two terms on the right denote the variation of the sediment mass in the water column from $t_{1}$ to $t_{2}$, the third term on the right denotes the mass transfer by the flow advection, the last term on the right denotes the sediment deposition from $t_{1}$ to $t_{2}$. The eq. (11) describe the sediment mass balance in the water column.

Having the vertical profiles of the suspended sediment $\mathrm{S}\left(t_{1}\right)$ and $\mathrm{S}\left(t_{2}\right)$ we can use eq. (11), to estimate the total erosion over the period from $t_{1}$ to $t_{2}$. The sediment profile can be expressed by the Rouse formula eq. (B2) in Supplementary Material (Appendix B). $\mathrm{S}_{a}$ can be referred to as $\mathrm{S}_{r}$, which is obtained from the GOCI retrieval model in eq. (10), the reference height can be set at the height of $0.2 \mathrm{~m}$ below the surface according to the optical depth in Lake Taihu. Therefore, the first two terms at the righthand side of eq. (11) can be derived through numerical integration. The advective term $F_{A d v}$ can be computed by the finite volume method using the current field by a hydrodynamic model. The deposition term at the righthand side of eq. (11) can also be calculated through eq. (6) for every time step. Finally, we can derive the total erosion over the period from $t_{1}$ to $t_{2}$ based on the GOCI retrieved sediment concentration field, and the model predicted current field.

\section{The critical shear stress}

Eq. (7) shows that $t_{c e}$ is a crucial parameter that controls the spatial distribution of the erosion flux. The value of $t_{c e}$ varies widely according to the sediment type, composition, and consolidation. For example, the values of $t_{c e}$ for mud and sand beds vary over a wide range (Parchure and Mehta, 1985). A traditional approach to determining $t_{c e}$ is via laboratory experiment using spot samples. Unfortunately, spot samples are limited by costs and sampling conditions. Consequently, an accurate spatial distribution of $t_{c e}$ in Lake Taihu has not existed until now. Thus, most previous sediment simulations used spatially uniform values of $t_{c e}$ to estimate the erosion flux. Ignoring the spatial variation in $t_{c e}$ is considered the major reason of the existing sediment models' inaccuracies.

By integrating eq. (7) from the period $t_{l}$ to $t_{2}$, we can convert eq. (7) to the following form:

$$
\tau_{c e}=\frac{\int_{11}^{2} \tau_{b} d t}{\left\{\int_{11}^{2} E d t /[(1-\delta) M]+t_{2}-t_{1}\right\}}
$$

The GOCI model provides high spatial and temporal coverage of the retrieved sediment concentration in Lake Taihu, with a horizontal resolution of $300 \mathrm{~m}$ at hourly intervals for eight hours every day. Hence, it is suitable for calibrating the distribution of $t_{c e}$ in the lake using eq. (12) combined with the erosion flux derived from the GOCI in eq. (11). The value of $t_{c e}$ is determined by the properties of the sediment, so it is thought to be stable in the short term.

\section{RESULTS}

Buoys, located in MB, SWL, and GL (shown in Fig. 1) measure real-time wind data. The measurements (shown in Fig. 2) suggest that the southerly and southeasterly winds dominate for most of the day (August 6, 2013) except for a short period after the noontime, and the wind magnitude ranges from 0.6 to $6.7 \mathrm{~m} \mathrm{~s}^{-1}$. Numerous observations indicate that the threshold value of wind speed for massive sediment resuspension is $6.5 \mathrm{~m} \mathrm{~s}^{-1}$ (Qin et al., 2007). Thus, we can assume that, on that day, a certain amount of sediment rather than massive sediment was suspended under the meteorological conditions.

The domain was horizontally discretized into triangle meshes with mean sizes of approximately $100 \mathrm{~m}$, and the depth was vertically divided into five layers using sigma coordinates. The selected integration time step was $30 \mathrm{~s}$. As a test, the flow was first simulated based on a stable southeasterly wind with a magnitude of $4.5 \mathrm{~m} \mathrm{~s}^{-1}$. For a short while, the flow ramped up to a stable current circulation. The prevailing flow on the surface followed the wind direction (Fig. 3a), while that near the bottom was against the wind (Fig. 3b). The average flow pattern showed that there is a large-scale clockwise eddy located at the western bank of Lake Taihu and an anticlockwise eddy in northern Lake Taihu (Fig. 3c). Driven by the wind, the flow is also influenced by the geometry of the lake basin, which is lower and broader in the west than in the east (Fig. 3d). The characteristics of the simulated 
velocity field were generally in agreement with observations and previous simulations (Pang et al., 2006; Hu et al., 2011).

The distributions of significant wave height $\left(H_{s}\right)$ and significant wave period $\left(T_{s}\right)$ are mainly determined by the wind fetch and depth. Under the impact of the southeasterly winds, $H_{s}$ and $T_{s}$ in the northwestern area of the lake, which has a long fetch and a large depth, are larger than are those in the eastern areas (Fig. 4). Waves are considered the most important factors that flush the bed and cause the resuspension of the sediment particles into the overlying water body. The wave-induced shear stress at the lake bottom was found to be much larger than the one caused by currents (Luo and Qin, 2003). The areas with high shear stress are mainly distributed near the NWL, MB, and SWL shores; these regions present shallow topography and large $H_{s}$ values.

After the above tests, an integration of the hydrodynamic model and GOCI sensing was applied to derive the erosion flux on August 6, 2013. The hourlyinterval concentration fields obtained by GOCI provided a short interval for integrating eq. (11). During that interval, the sediment distribution was determined by the combined processes of erosion, deposition, and horizontal advection. We compared the three terms and found that the advection term was small compared to the erosion and deposition terms during the short time (shown in Fig. 5). Therefore, it can be concluded that the horizontal transport by wind-driven currents is not very important in the estimation of the erosion flux during a short time.

Next, the critical shear stress was derived based on the averaged erosion flux by using eq. (12). Fig. 6 shows the distribution of the critical shear stress across the lake. The amplitude of $t_{c e}$ ranges from 0.02 to $0.3 \mathrm{Nm}^{-2}$ in a spatially varying pattern. The areas with large $t_{c e}$ values are mainly distributed near the western portion of the lake, the north shore and in some straits, where wave-induced shear and current-induced flushing are strong. Conversely, the areas with small $t_{c e}$ values are distributed near the east shore and deep locations far from the shore. Various factors, such as the prevailing wind, the topography, the mud depth, and the sediment composition, would affect the erosion and

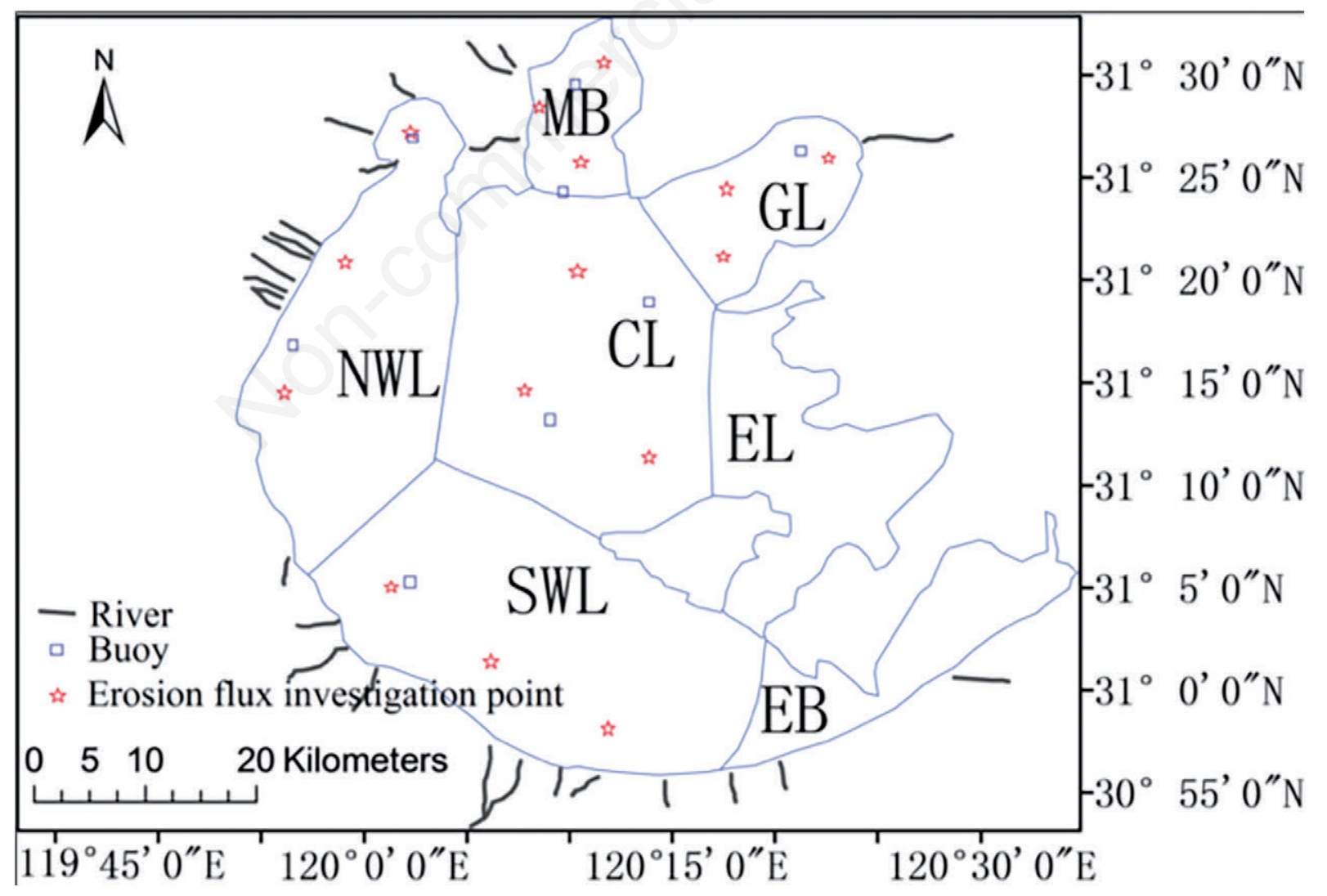

Fig. 1. The seven subdivisions of Lake Taihu including Meiliang Bay (MB), Central Lake (CL), Gong Lake (GL), Northwestern Lake (NWL), Southwestern Lake (SWL), East Lake (EL), and Eastern Bay (EB). The squares denote the location of Buoys and stars denote the erosion flux investigation point. 
the distribution of $t_{c e}$. Some discussions about the erosion distribution are conducted in the next section.

To demonstrate the validity of the GOCI-derived critical shear stress, we conducted a numerical simulation using the spatially uniform and GOCI-derived critical shear stress respectively. The results produced using the GOCI-derived critical shear stress (Fig. 7a) were compared to those using the spatially uniform critical shear stress (Fig. 7b). Qin et al. (2007) revealed that the critical shear stress associated with the sediment resuspension from the bed ranged between 0.03 and $0.04 \mathrm{~N} \mathrm{~m}^{-2}$. Thus, we used $t_{c e}=0.04 \mathrm{~N} \mathrm{~m}^{-2}$ as the spatially uniform critical shear stress for comparison. The overall distributions of the erosion flux are similar, suggesting that the coupled model is mechanically reasonable. However, the differences are obvious in some places. For example, near the SWL coast, the result associated with the uniform critical shear stress is much larger than the one associated with variable critical shear stress. In MB and Zhushan Bay located in the northern NWL, the distribution of the two results is also very different. These results show that areas with high erosion are distributed near the northwestern shore of the lake, the northwestern shore of MB and the northern shore of GL. The sediment concentration is relatively high in these areas. The turbidity values measured by buoys located in MB, CL, NWL, SWL and GL (shown in Fig. $8 \mathrm{a})$ are used to validate and compare the model results shown in Fig. 8b. The RMSE (root mean square error) for the GOCI-derived spatially variable critical shear stress model is $12.8 \mathrm{mg} \mathrm{L}^{-1}$, much less than the $22.5 \mathrm{mg} \mathrm{L}^{-1}$ obtained with the uniform critical shear stress, which means that the results produced using GOCI-derived spatially variable critical shear stress are more consistent with the measurements than those obtained by using the fixed uniform critical shear stress. The reason is that the uniform critical shear stress method tends to overestimate the sediment concentration in NWL due to underestimation of the critical shear stress.

(a)

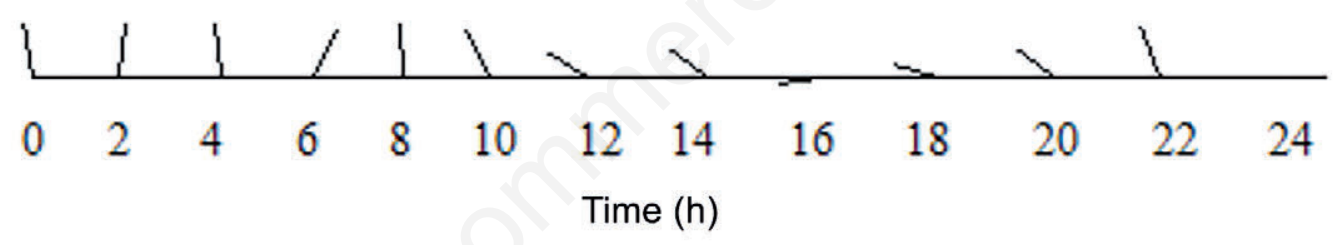

(b)

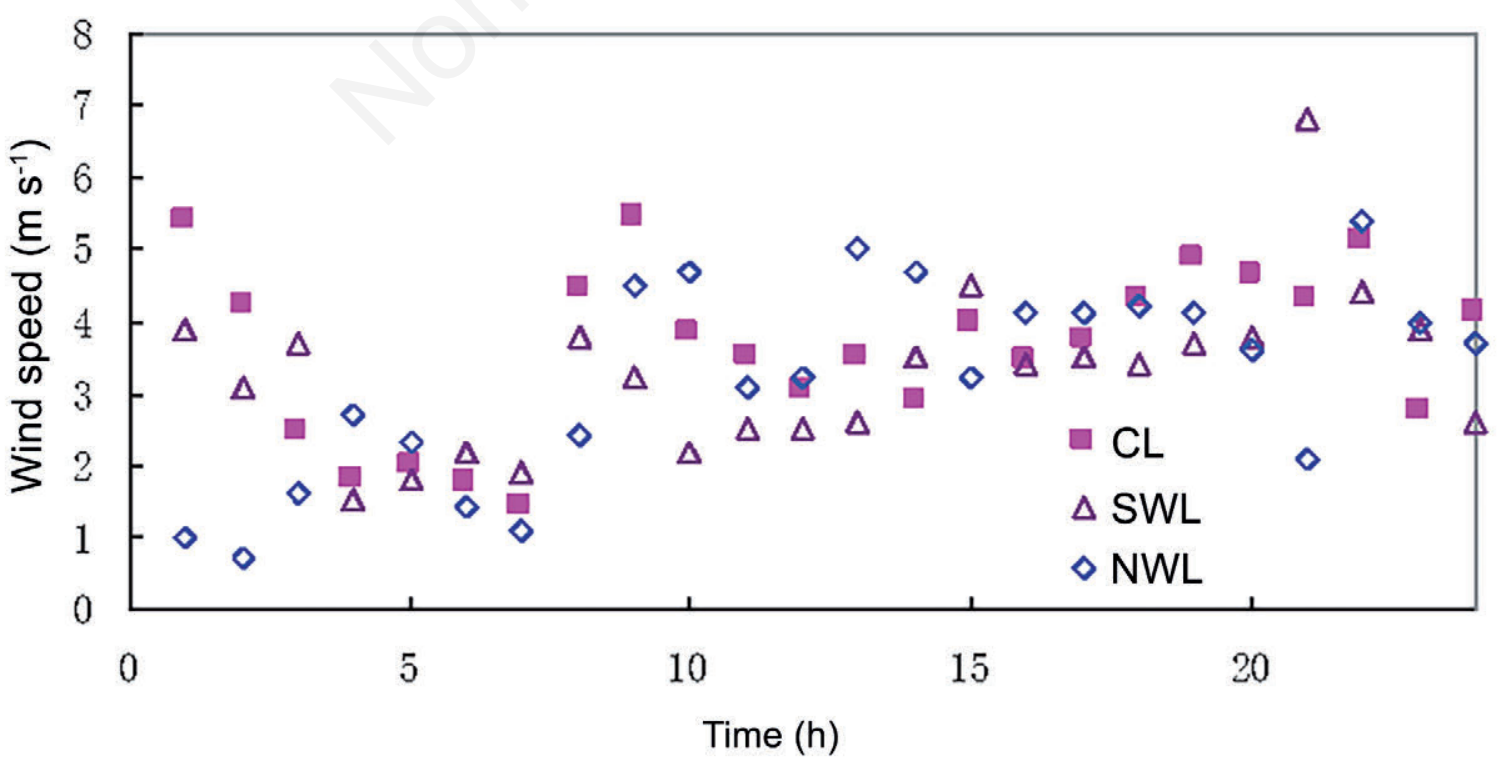

Fig. 2. The 24 hours wind direction (a) and speed (b) measured by the buoys on August 6, 2013. 


\section{DISCUSSION}

\section{The factors influencing the erosion flux distribution}

Various factors influence the spatial distribution of the erosion flux, including wind speed, wind fetch, mud depth, and water depth. Li et al. $(2007,2009)$ established an empirical relationship between the erosion flux and wind speed and applied it in numerical simulations. However, that study was based on only a few samples from the Meiliang Bay (MB) in Lake Taihu. Moreover, the erosion flux must be attributed to more factors than solely wind speed. Therefore, this work investigated the relationships between the erosion flux and four other factors based on the erosion flux field. To take the spatial variation for different subsections in Lake Taihu into account, three spots were chosen in each subsection except EL and EB (Fig. 1). Twenty-one hourly erosion fluxes were computed at each spot using eq. (11) during the three days (August 6-8). These samples were used to

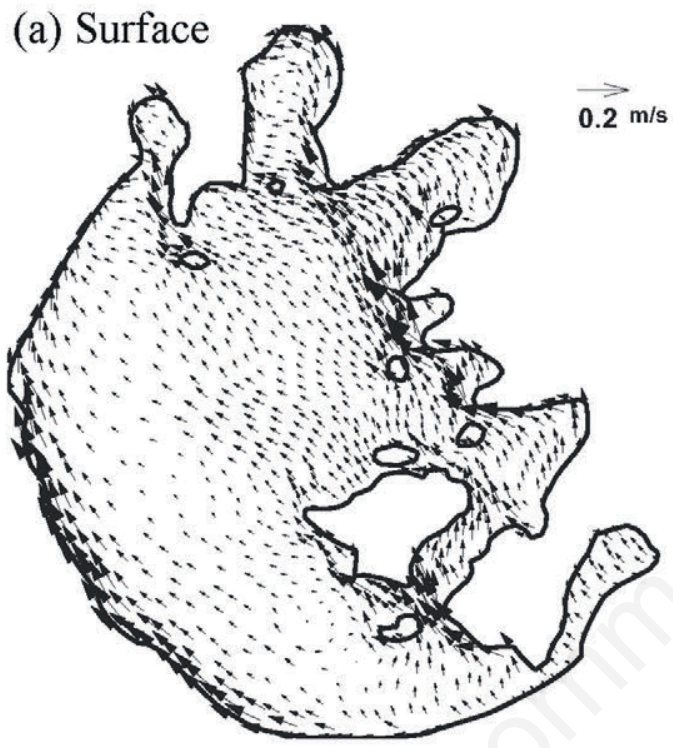

(c) Depth averaged

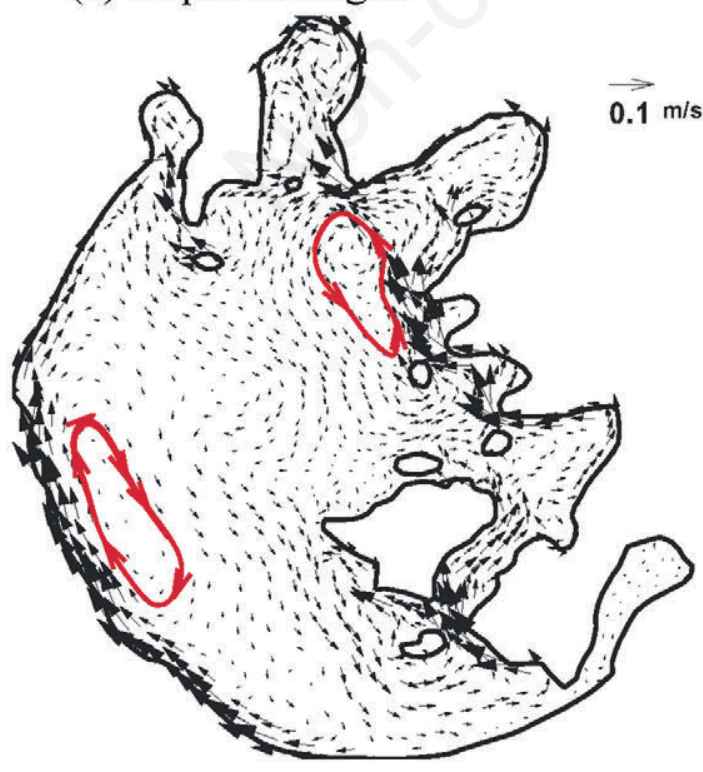

(b) Bottom

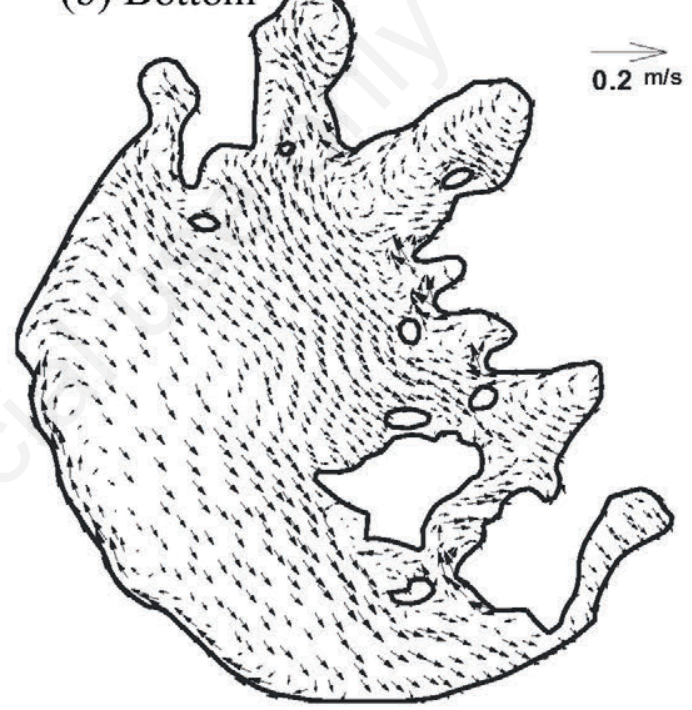

(d) Bathymetry

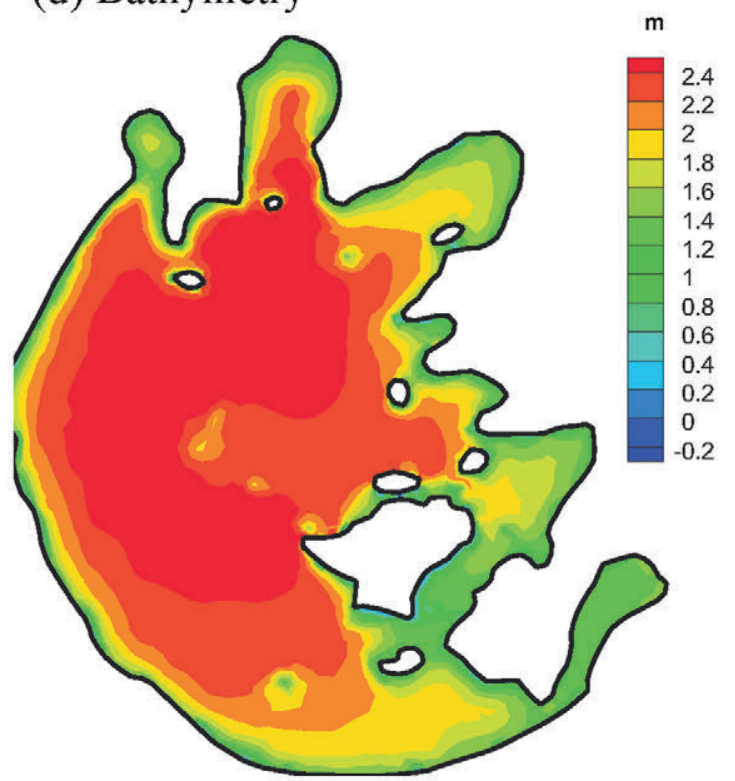

Fig. 3. The vectors of the flow field near the surface (a) and bottom (b) and vertically averaged (c) in Lake Taihu under consistently southeasterly wind with a speed of $4.5 \mathrm{~m} / \mathrm{s}$, and the topography (d). 
account for temporal variations. Fig. 9 through Fig. 12 show the various erosion fluxes between different spots and subsections at different times. The figures demonstrate the influence of spatial heterogeneity on the sediment suspension in Lake Taihu.

Many scholars have found a positive correlation between the erosion flux and wind speed (Li et al., 2007; 2009), some of them have even presented empirical formulas to estimate erosion (Li et al., 2007; 2009). Unfortunately, due to the sparsity of the sampling, their results are more applicable to local points rather than the whole lake. As shown in Fig. 9, the general correlation between the erosion flux and wind speed is weak, with a correlation coefficient of only 0.016 , and the sample data are scattered. The difference between every subsection of the lake is notable. In MB areas, a weak positive correlation appears, in accordance with the results of other studies. In GL, CL, and SWL areas, the positive correlation is not so clear. We consider that, in addition to wind speed, wind direction is possible more affected by the erosion flux. As precise observations of wind direction are difficult to obtain, the direction of the prevailing wind over southeast Lake Taihu in summer was used to estimate the wind fetch. Fig. 10 shows that the correlation between wind fetch and erosion is also weak, with a positive correlation coefficient $\mathrm{R}^{2}$ of only 0.018 . For every subsection, open areas, such as NWL and CL, show a weak positive correlation. In contrast, semi-enclosed bay areas show almost no correlation between the wind fetch and erosion flux. This is because the wind-driven waves in the bay are more complicated owing to refraction and diffraction there. Mud is considered the source of the erosion flux. Fig. 11 demonstrates a weak positive correlation between the mud depth and the erosion flux, with a correlation coefficient of 0.022 . This shows that high erosion in MB areas results from the presence of a thick layer of mud. Finally, Fig. 12 shows a weak negative correlation between water depth and erosion flux, with a correlation coefficient of only 0.003 . This indicates that the effect of depth on erosion is not notable compared to other factors.

\section{Problems about the suspended sediment model}

With the advances in numerical modeling, more advanced suspended sediment models have been developed in recent years. However, their performances vary in different fields. Generally, over the last decade, the sediment model performed much better in rivers and estuaries (Warner et al., 2008; Pandoe and Edge, 2008; Harris et al., 2008) than in lakes (Stroud et al., 2009; Cardenas et al., 2005). The reason is that the currents are the major dynamical factor in rivers and estuaries but not in most shallow lakes (Luo and Qin, 2003; Luo et al., 2004). Due to its shallow topography and open surface, Lake Taihu is characterized by a wave-induced dynamical field, where the shear stress caused by waves is generally much larger than that caused by currents. Even though (a) Significant wave height

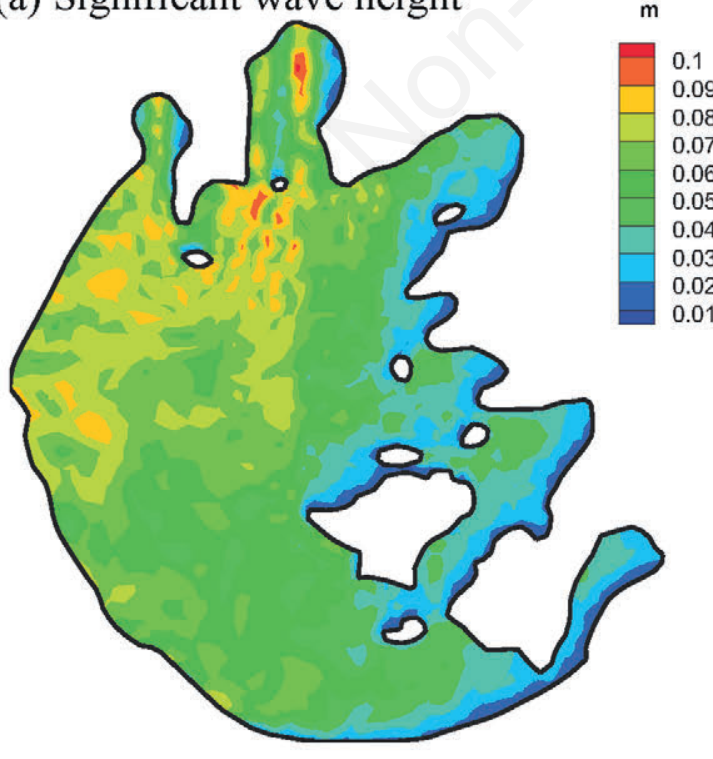

(b) Significant wave period

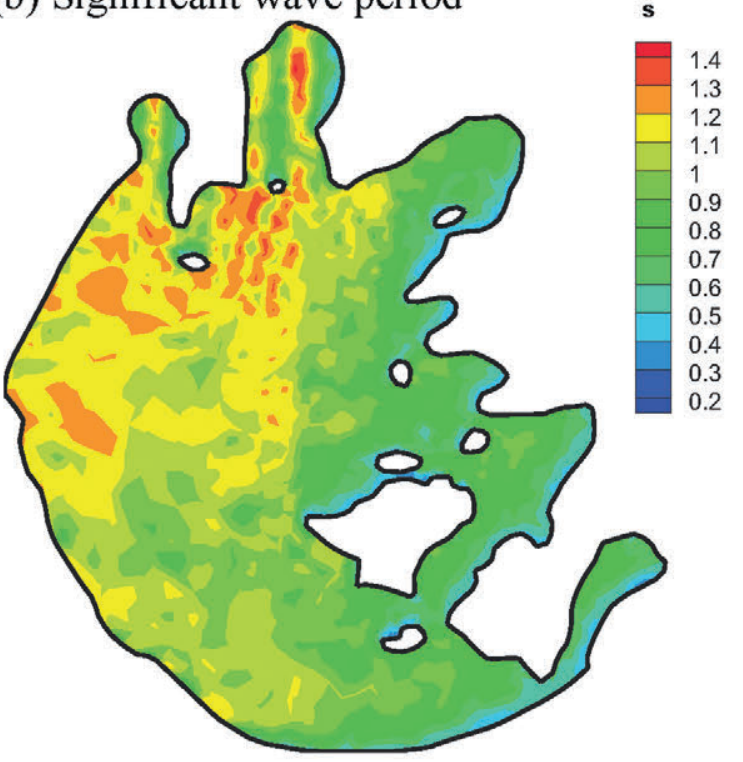

Fig. 4. The wave field: (a) significant wave height; (b) significant wave period by SMB model under consistently SE wind with a speed of $4.5 \mathrm{~m} \mathrm{~s}^{-1}$. 
some sediment models have taken waves into account, most of them focus on currents, and thus their direct application to the Lake Taihu may yield unsatisfactory results (Pang et al., 2006).

The inaccuracies in sediment models are related to three aspects: First, the heterogeneous compositions of the sediment and mud depth results in heterogeneous values of critical shear stress. Second, the empirical wave (b) Deposition

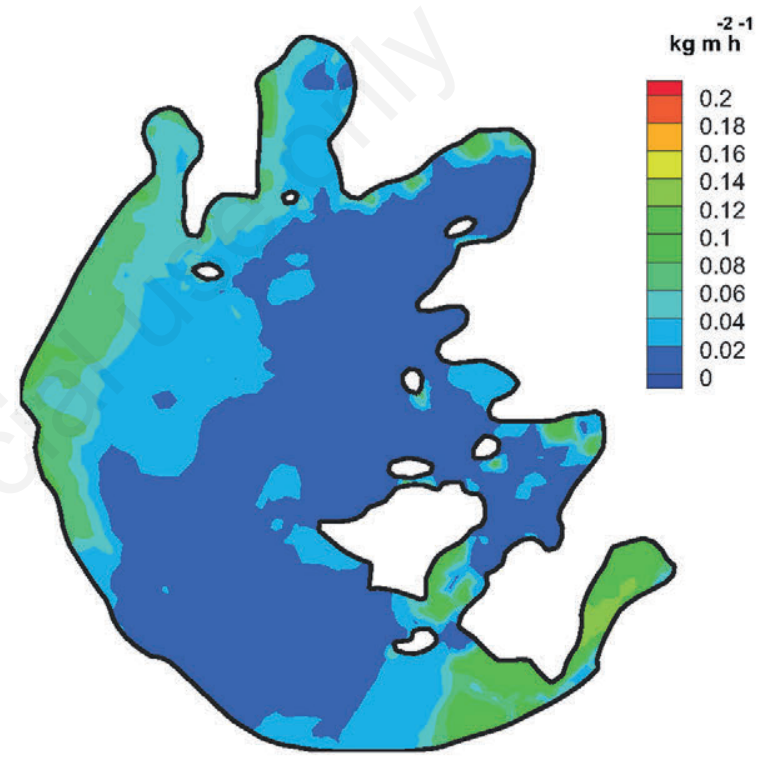

(c) Advection

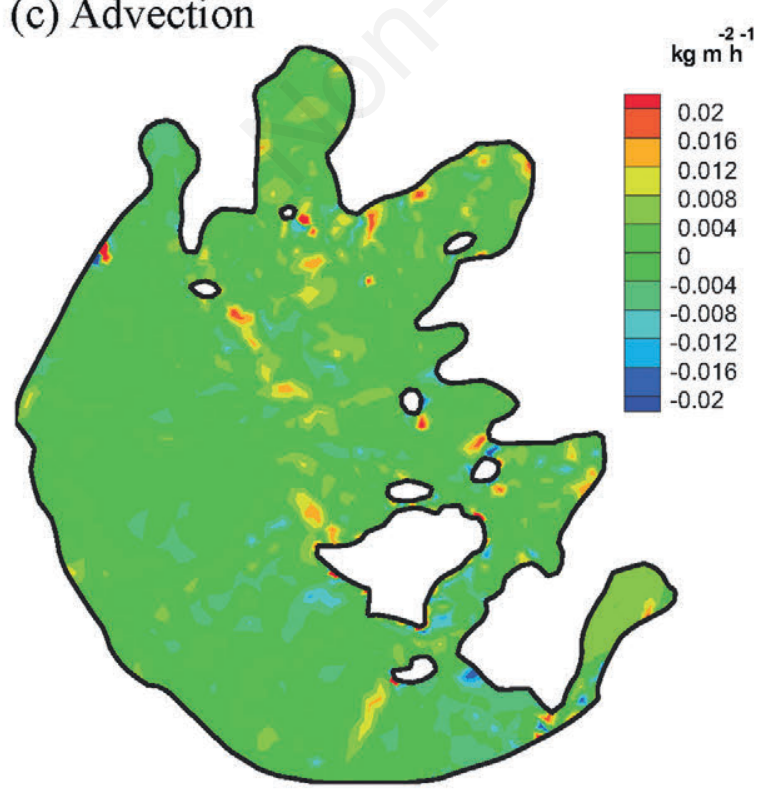

model cannot accurately reflect some of the complicated processes of wave propagation such as diffraction, refraction, and reflection, especially in semi-enclosed bays. Last but most importantly, inaccuracies in the wind record increase the model uncertainty. Wind is a heterogeneous and rapidly changing parameter that affects waves and current simulations. Simple aerovanes in sparsely distributed locations cannot supply a high-

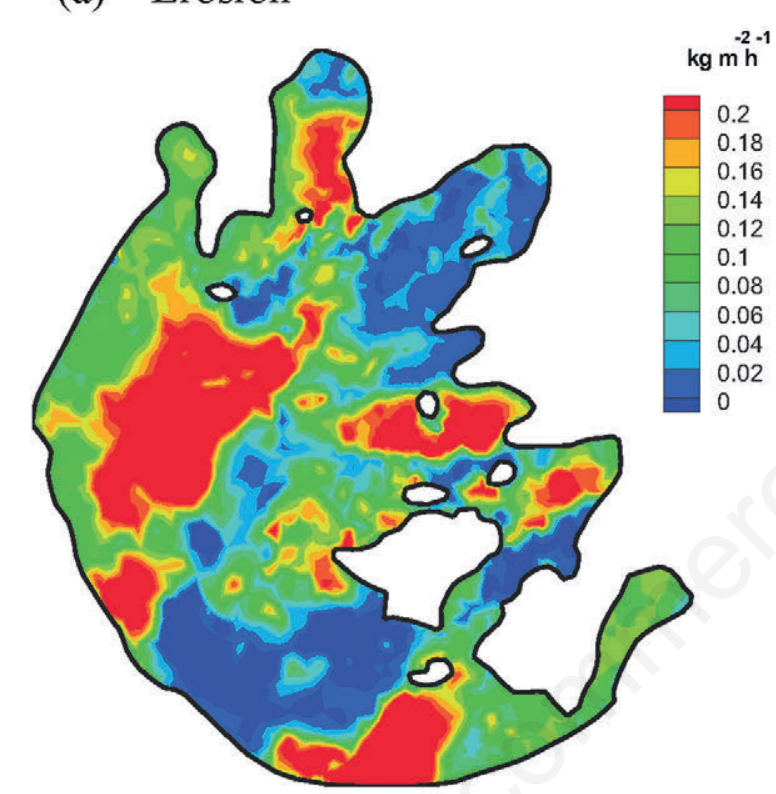

(a) Erosion 
resolution and accurate synchronous wind field data for the hydrodynamic modeling. For example, the accuracy of the wind direction measurement is only $\pm 5^{\circ}$, introducing large errors into the calculations of the wind fetch and the significant wave height.

Two approaches can be used to solve this problem. The first one is improving the models. For example, the mechanical SWAN model (Booij et al., 1999) can be used to model the waves instead of the empirical wave model. The WRF model (Skamarock, 2005) can be applied to supply the high-resolution and synchronous wind field inputs instead of using low-accuracy monitoring data. The second approach is optimizing the parameters in existing models of a certain lake. For suspended sediment simulations in Lake Taihu, the variable critical shear stress is not only a physical parameter reflecting the sediment properties of the bed but also a numerical tuning parameter that counteracts the errors associated with wave prediction and wind field simplification. Sparse spot measurements cannot supply synchronously highresolution concentration to derive the critical shear stress field. However, this study proposes that the remote sensing, which allows synchronous and timely retrieval of sediment concentrations over a large area, provides a feasible approach to calibrating the spatially varying critical shear stress field. The model results were improved by using the calibrated critical shear stress in this paper.

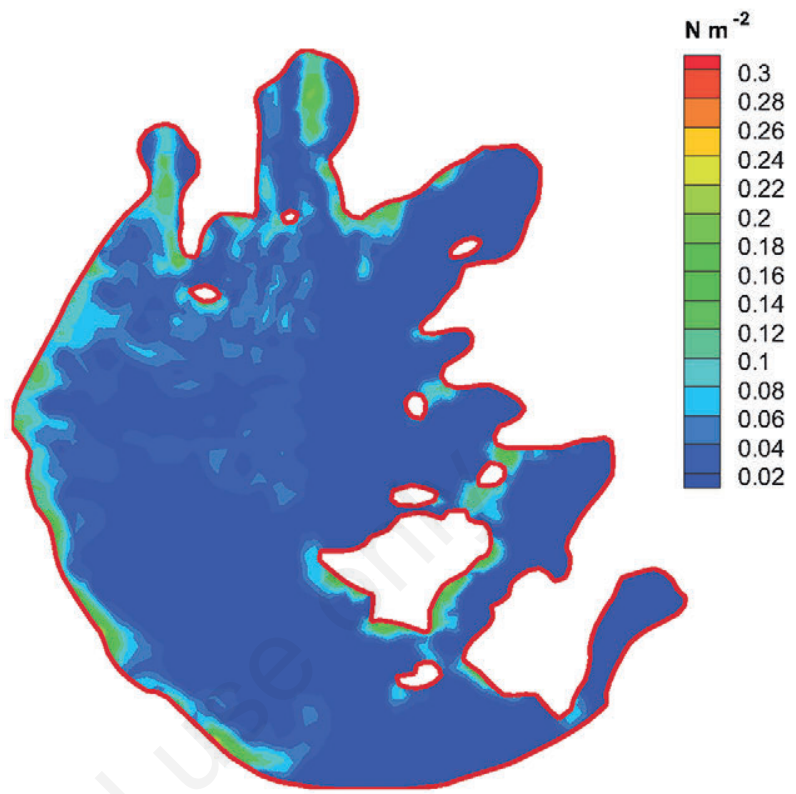

Fig. 6. Distribution of the derived critical shear stress $\left(t_{c e}\right)$ in Lake Taihu. (a) Variable critical stress

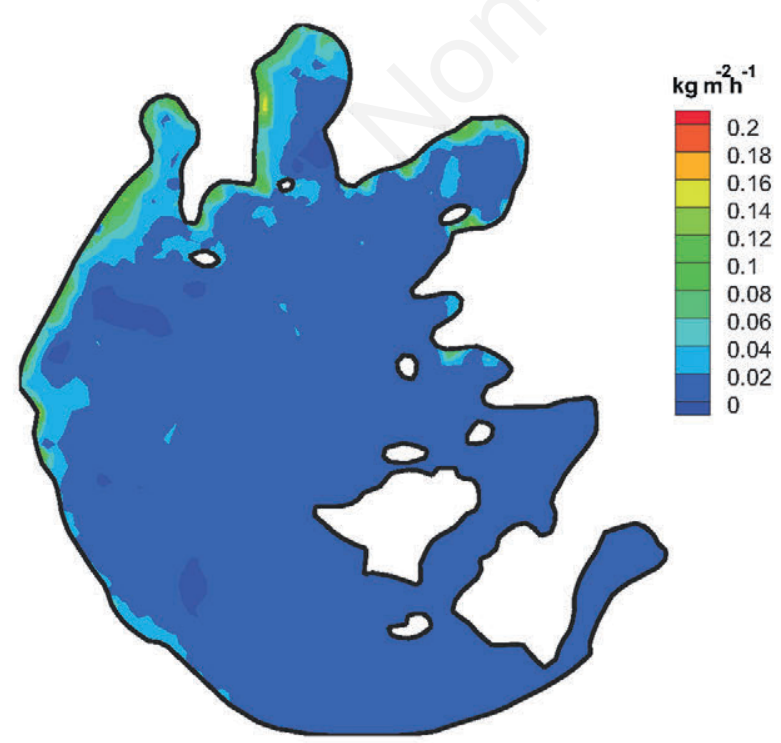

(b) Uniform critical stress

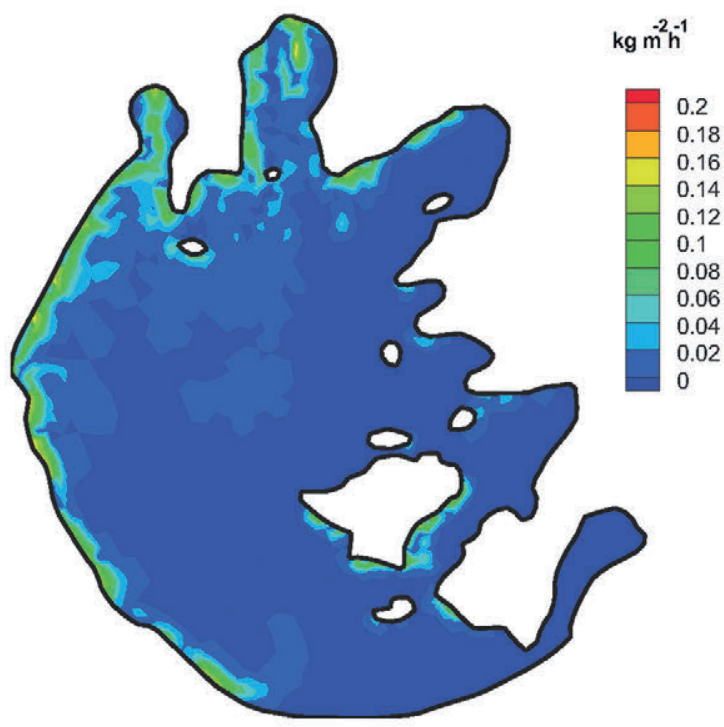

Fig. 7. Comparison of the erosion flux derived by (a) the GOCI-derived critical shear stress and (b) the spatially uniform critical shear stress. 


\section{CONCLUSIONS}

In this study, GOCI sensing data were integrated with a numerical model to derive the spatial distribution of erosion, which is determined using the mass conservation equations between the erosion, deposition, and advection of suspended sediment. We found that the balance between erosion and deposition dominates, and advection is much less important over short periods. Then, the distribution of the critical shear stress over the lake was estimated based on the average erosion flux. We observed large values of critical shear stress in the western part of the lake, near the northern shore and in the straits of the lake; small values were observed in the central and eastern parts of the lake. Next, simulations were performed to compare the results obtained using the conventional method of applying a uniform critical shear stress and those produced using a spatially variable critical shear (a)

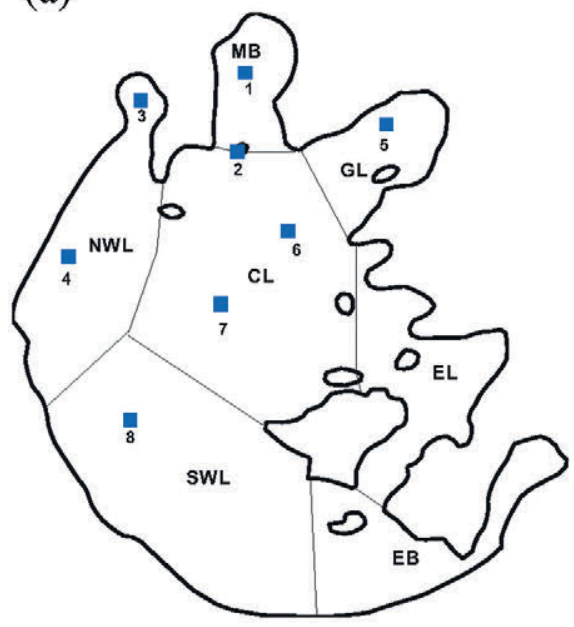

(b)

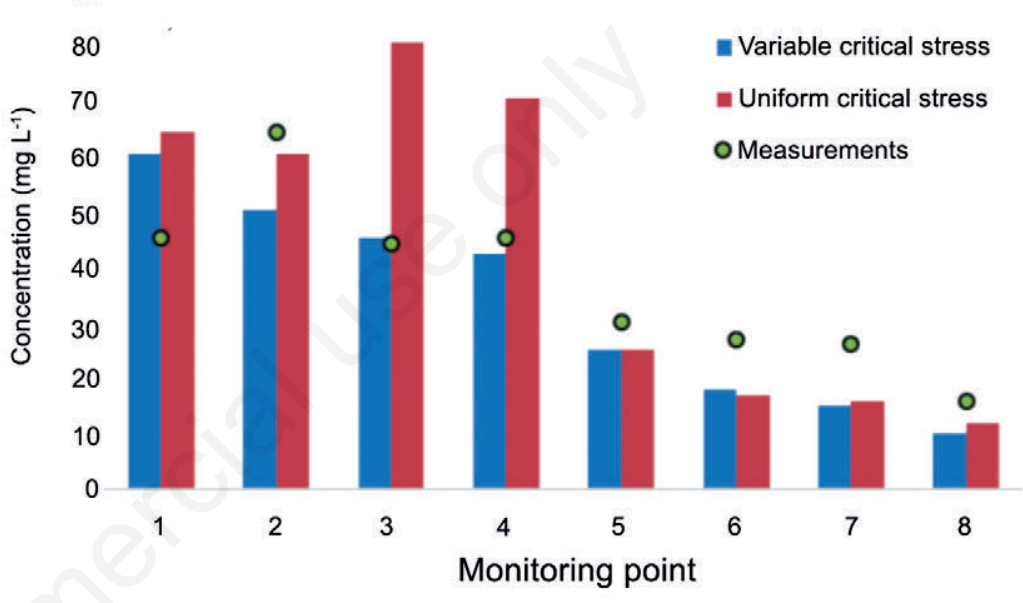

Fig. 8. Comparison of the model results (using the GOCI-derived critical shear stress and uniform critical shear stress) with measured data from the buoys.

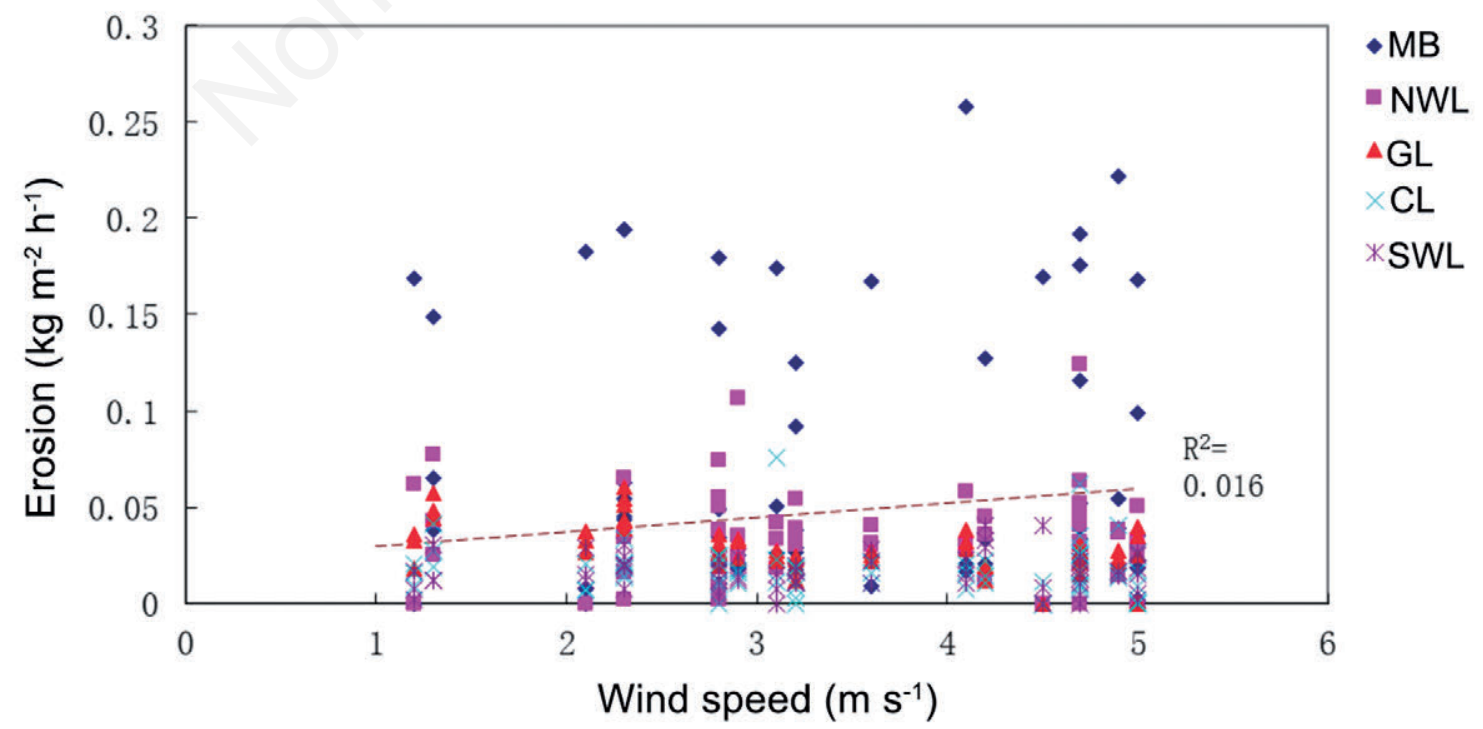

Fig. 9. Relationship between erosion and wind speed for five subsections in Lake Taihu. The dashed line is the fitting line with the correlation coefficient $\mathrm{R}^{2}$. 
stress. We found that the latter provided results that were more consistent with buoy-measured data. Therefore, using GOCI sensing data to improve model results is a feasible approach in sediment simulations of Lake Taihu. Finally, the major factors that influence the spatial distribution of the erosion flux were analyzed over a three-day period in 15 spots located in 5 subsections of
Lake Taihu. The investigation showed that the spatial distribution of sediment suspension varies in the lake. In addition to wind speed, which has been noted by previous studies, wind fetch, mud depth, and water depth also exhibit an important influence over the erosion flux. After that some of the problems of the sediment model are also discussed.

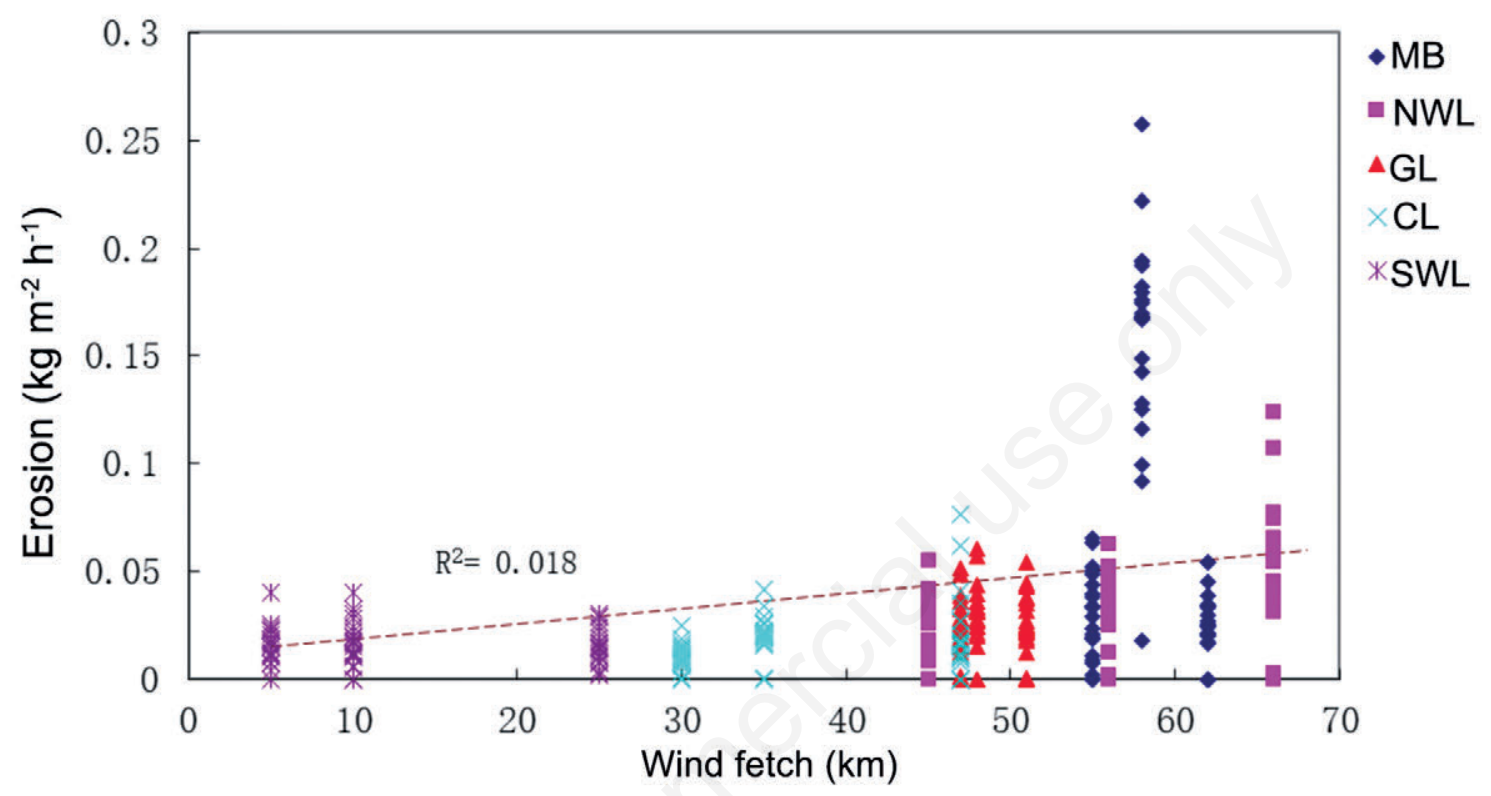

Fig. 10. The same as Fig. 9 except for the relationship between erosion and wind fetch.

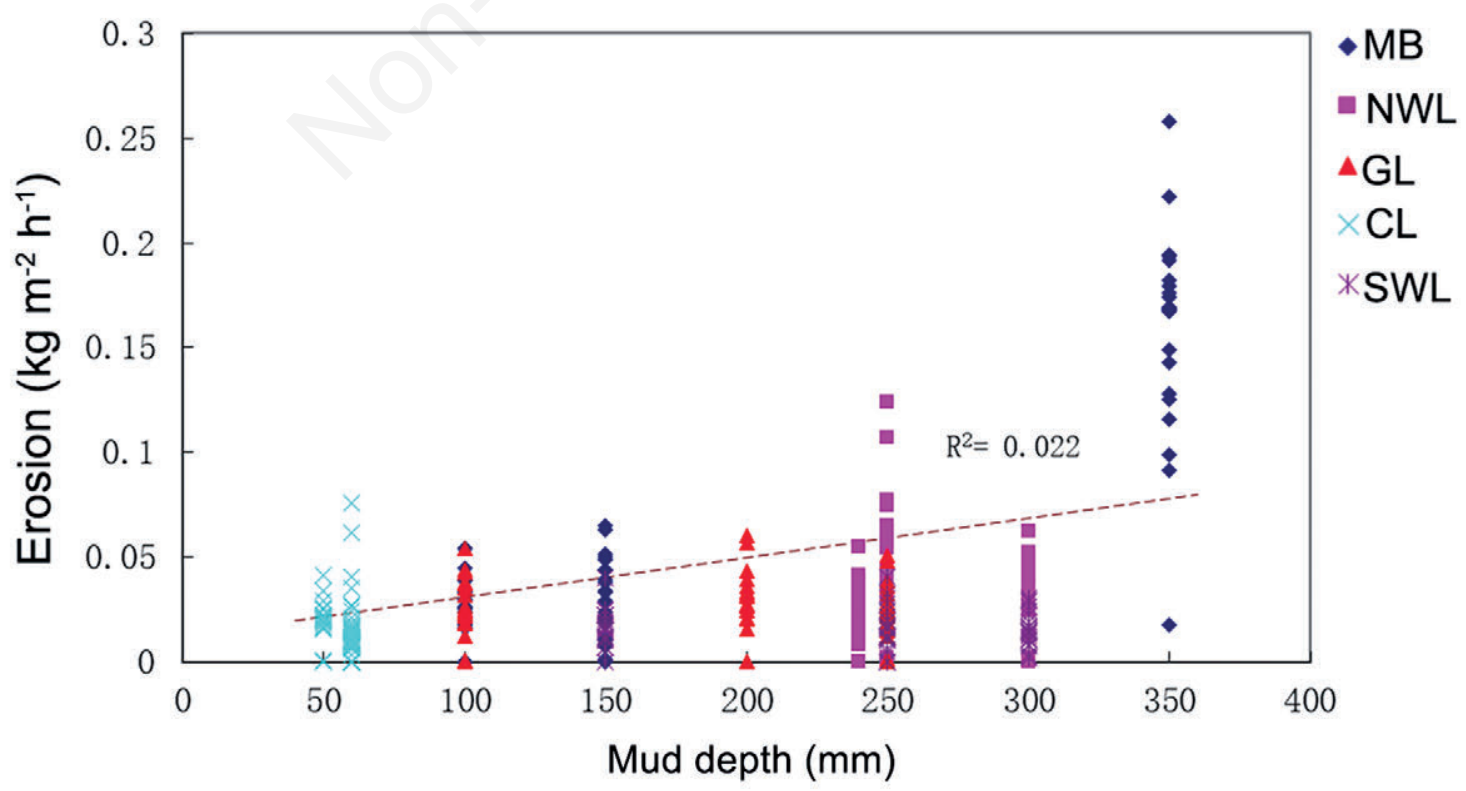

Fig. 11. The same as Fig. 9 except for the relationship between erosion and mud depth. 


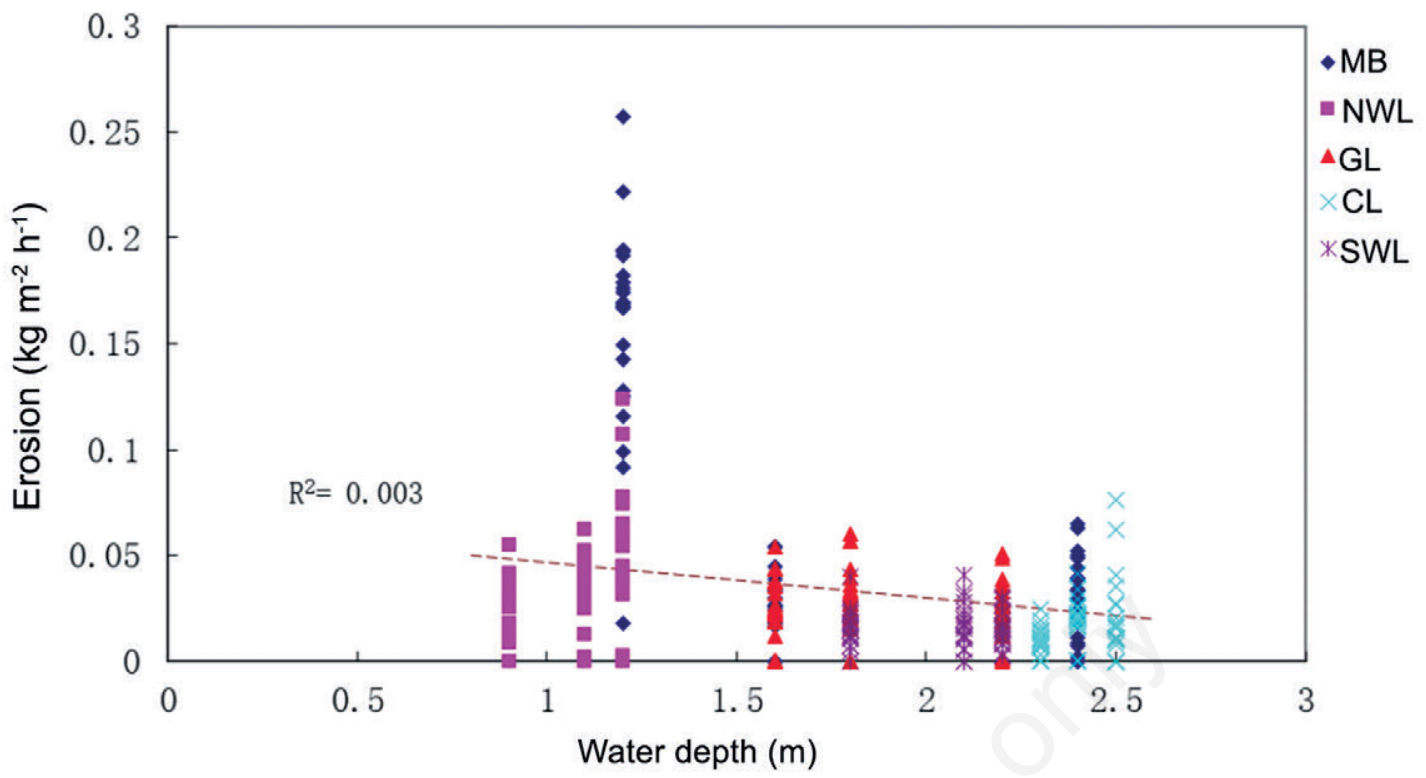

Fig. 12. The same as Fig. 9 except for the relationship between erosion and water depth.

\section{ACKNOWLEDGMENTS}

The paper was supported by National Natural Science Foundation of China (grant No. 41571324). The authors thank the Korea Ocean Satellite Center for providing the GOCI data and two anonymous reviewers for their helpful suggestions.

\section{REFERENCES}

Booij N, Ris R, Holthuijsen L, 1999. A third-generation wave model for coastal regions, part i: model description and validation. J. Geophys. Res. 104:7649-7666.

Cardenas MP, Schwab DJ, Eadie BJ, Hawley N, Lesht BM. 2005. Sediment transport model validation in Lake Michigan. J. Great Lakes Res. 31:373-385.

Casulli V, Cattani E, 1993. Stability accuracy and efficiency of a semiimplicit method for three-dimensional shallow water flow. Computers Math. Appl. 27:99-112.

Casulli V, Walters RA, 2000. An unstructured grid, three-dimensional model based on the shallow water equations. International Int. J. Numer. Math. Fl. 32:331-348

Casulli V, Zanolli, P, 2005. High resolution methods for multidimensional advection-diffusion problems in free-surface hydrodynamics. Ocean Model. 10:137-151.

Chen C, Liu H, Beardsley R, 2003. An unstructured grid, finite-volume, three-dimensional, primitive equations ocean model: Application to coastal ocean and estuaries. J. Atm. Ocean Tech. 20:159-186.

Cho S, Ahn YH, Ryu JH, Kang GS, Youn HS, 2010. Development of Geostationary Ocean Color Image (GOCI) Korean J. Remote Sens. 26:157-165.

Chung EG, Bombardelli FA, Schladow SG, 2009. Modeling linkages between sediment resuspension and water quality in a shallow, eutrophic, wind-exposed lake. Ecol. Model. 220:1251-1265.
Douglas R W, Rippey B, 2000. The random redistribution of sediment by wind in a lake. Limnol. Oceanogr. 45:686-694.

Elliott JA, Perrson I, Thackeray SJ, Blencker T, 2007. Phytoplankton modelling of Lake Erken Sweden by linking the models PORBE and PROTECH. Ecol Model. 202:421-426.

Fan C, Zhang L, Qin B, Wang S, Hu W, Zhang C, 2004. Estimation on dynamic release of phosphorus from wind-induced suspended particulate matter in Lake Taihu. Sci. China Ser. D. 47:710-719.

Gailani J, Ziegler CK, Lick W, 1991. The transport of sediments in the Fox River. J. Great Lakes Res. 17:479-494.

Ge J, Shen F, Guo W, Chen C, Ding P, 2015. Estimation of critical shear stress for erosion in the Changjiang Estuary: A synergy research of observation, GOCI sensing and modeling. J. Geophys. Res. Oceans, 120:8439-8465

Gitelson AA, Schalles, JF, Hladis, CM, 2007. Remote chlorophylla retrieval in turbid, productive estuaries: Chesapeake Bay case study. Remote Sens. Environ. 109:464-472.

Hamrick JM, 1992a. A three-dimensional environmental fluid dynamics computer code: Theoretical and computational aspects. Virginia Institute of Marine Science, College of William and Mary, Gloucester Point: 126 pp.

Hamrick JM, 1992b. Estuarine environmental impact assessment using a three-dimensional circulation and transport model, p. 292-303. In: M.L. Spaulding et al. (eds.), Proceedings 2nd Int. Conf. on Estuarine and Coastal Modeling. Am. Soc. of Civ. Eng., New York.

Harris CK, Sherwood CR, Signell RP, Bever AJ, Warner JC, 2008. Sediment dispersal in the northwestern Adriatic Sea. J. Geophys. Res. 113:C11S03-

Hu K, Pang Y, Wang H, Wang X, Wu X, Bao K, Liu Q, 2011. Simulation study on water quality based on sediment release flume experiment in Lake Taihu, China. Ecol. Eng. 37:607-615.

$\mathrm{Hu}$ W, Jorgensen S, Zhang F, 2006. A vertical-compressed threedimensional ecological model in Lake Taihu, China. Ecol. Model. 190:367-398.

Huang C, Guo Y, Yang H, Li Y, Zou J, Zhang M, Lyu H, Zhu A, Huang $\mathrm{T}, 2015$. Using remote sensing to track variation in phosphorus and its interaction with clorophyll-a and suspended sediment. IEEE J. Sel. Top. Appl. 8:4171-4180. 
Huang J, Gao J, Hormann G, 2012. Hydrodynamic-phytoplankton model for short-term forecasts of phytoplankton in Lake Taihu, China. Limnologica 42:7-18.

Kaitaranta J, Niemisto J, Buhvestova O, Nurminen L, 2013. Quantifying sediment resuspension and internal phosphorous loading in the shallow near shore areas in the Gulf of Finland, Boreal Environ. Res. 18:413-487.

Kong J, Xin P, Shen C, Song Z, Li L, 2013. A high-resolution method for the depth-integrated solute transport equation based on an unstructured mesh. Environ. Modell. Softw. 40:109-127.

Large WG, Pond S, 1981. Open ocean momentum flux measurements in moderate to strong winds. J. Phys. Oceanogr. 11:324-336

Li R, Luo F, Zhu W, 2008. Suspended sediment movement equation and near bottom flux. Sci. Chin. Ser. E 38:1995-2000.

Li Y, Pang Y, Lv J, 2004. [On the relation between the release rate of TN, TP from sediment and water velocity].[Article in Chinese]. J. Lake Sci. 16:318-324.

Li Y, Pang Y, Li Y, 2007. [Resuspended flux of sediment in Taihu Lake under hydrodynamic action].[Article in Chinese]. J. Hydraul. Eng. 38:558-564.

Li Y, Pang Y, Luo L, 2009. [Experimental and numerical study on the transfer process of suspended matter in the interaction of wave and current in Taihu Lake].[Article in Chinese]. Adv. Water Sci. 20:701706.

Luo L, Qin B, 2003. [Comparison between wave effects and current effects on sediment resuspension in Lake Taihu].[Article in Chinese]. Hydrology 23:1-4

Luo L, Qin B, Hu W, Ji J., Zhang F, 2004. [Wave characteristics in Lake Taihu].[Article in Chinese]. J. Hydrodyn. Ser. A. 19:664-670.

Maa J, Kwon J, Hwang K, Ha H, 2008. Critical bed-shear stress for cohesive sediment deposition under steady flows. J. Hydraul. Eng. 134:1767.

Mao J, Chen Q, Chen Y, 2007. Three-dimensional eutrophication model and application to Taihu Lake, China. J. Environ. Sci. 20:278-284.

Mellor GL, Yamada T, 1982. Development of a turbulence closure model for geophysical fluid problem. Rev. Geophys. 20:851- 875.

Pang Y, Li Y, Luo L, 2006. Study on the simulation of transparency of Lake Taihu under different hydrodynamic conditions. Sci. Chin. Ser. D. 49:162-175.

Pandoe WW, Edge BL, 2008. Case study for a cohesive sediment transport model for Matagorda Bay, Texas, with coupled ADCIRC 2D-Transport and SWAN wave models. J. Hydraul. Eng. 134:303314.
Parchure TM, Mehta AJ, 1985. Erosion of soft cohesive sediment deposits. J. Hydraul. Eng. 111:1308-1326.

Qin B, 2009. Lake eutrophication: control countermeasures and recycling exploitation. Ecol. Eng. 35:1569-1573

Qin B, Liu G, Havens KE, 2007. Eutrophication of shallow lakes with special reference to Lake Taihu, China. Springer, Dordrecht: 328 pp.

Rouse H, 1938. Experiments on the mechanics of sediment suspension, p. 550-554. In Proceedings 5th Int. Congr. Applied Mechanics, Cambridge.

Schladow SG, Hamilton DP, 1997. Prediction of water quality in lakes and reservoirs: Part $\square$ Model calibration, sensitivity analysis and application. Ecol. Model. 96:111-123.

Skamarock WC, 2005. A description of the advanced research WRF version 3. NCAR Technical Note NCAR/TN-475+STR, doi:10.5065/D68S4MVH.

Stroud JR, Lesht BM, Schwab DJ, Beletsky D, Stein M L, 2009. Assimilation of satellite images into a sediment transport model of Lake Michigan. Water Resour. Res. 45:W02419.

Thompson CEL, Couceiro F, Fones GR, Helsby R, Amos CL, Black K, Parker ER, Greenwood N, Statham PJ, Kelly-Gerreyn B, 2011. In situ flume measurements of resuspension in the North Sea. Estuar. Coast. Shelf Sci. 94:77-88.

Warner J, Sherwood C, Signell R, Harris C, Arango H, 2008. Development of a three-dimensional, regional, coupled wave, current, and sediment-transport model, Comput. Geosci. 34:12841306.

Xin W, 1997. [Numerical model of 2D estuarial suspended sediment motion under the interaction of tidal flow and waves].[Article in Chinese]. Ocean Eng. 15:30-47.

Zhang H, Culver D A, Boegman L, 2008. A two-dimensional ecological model of Lake Erie: application to estimate dreissenid impacts on large lake plankton population. Ecol. Model. 214:219-240.

Zhang Z, Song Z, Kong J, Hu D, 2016. A new r-ratio formulation for TVD schemes for vertex-centered FVM on an unstructured mesh. Int. J. Numer. Meth. F1. 81:741-764.

Zheng L, Chen C, Alber M, Liu H, 2003. A 3-D modeling study of the Satilla River Estuarine System. Part $\square$ : Suspended sedimentation. Estuaries 26:670-679.

Zhu G, Qin B, Gao G, 2005. [Direct evidence of phosphorus outbreak release from sediment to overlying water in a large shallow lake caused by strong wind wave disturbance].[Article in Chinese]. Chin. Sci. Bull. 50:577-582. 